DOI: 10.2478 /ausp-2019-0022

\title{
Linguistic Mediation in the Digital Age
}

\author{
Ildikó HORVÁTH \\ Department of Translation and Interpreting \\ Institute of Language Mediation/Eötvös Loránd University \\ horvath.ildiko@btk.elte.hu
}

\begin{abstract}
Technological advances have had an impact not only on the translation but also on the interpretation market. Furthermore, with the advent and widespread use of new information and communication technologies (ICTs) in the field of language mediation, the professions traditionally called "translation" and "interpreting" have been transformed by the digital revolution. In times of upheaval, profound changes can be felt in the market, the working environment, the conditions and processes as well as in the way language mediators work, the tasks they carry out, and the roles they play in the translation process. In the present article, we shall focus on these major changes and highlight the latest developments first in the field of translation and then in interpreting.
\end{abstract}

Keywords: linguistic mediation, language industry, Neural Machine Translation (NMT), HAT, AI interpreting

\section{Introduction: Linguistic mediation, transcultural communication, and the digital age}

Linguistic mediation is the generic term encompassing different types of content transfer from the source language to the target language. Traditionally, the field is divided into translation and interpreting, that is, written and oral linguistic mediation. However, there are "hybrid modes" as well (Felekné Csizmazia 2014, Horváth 2013, Parkin 2010) such as sight translation consisting in transferring a written text into its oral target-language equivalent. Sign language interpreting can also be considered as a "bimodal" mode of interpreting (Corina-Vaid, 1994). Technological advances have had an impact not only on the translation but also on the interpretation market (Horváth 2016). Furthermore, with the advent and widespread use of new information and communication technologies (ICTs) in the field of language mediation, new professions are emerging such as respeaking 
in audiovisual translation (Szarkowska-Krejtz-Dutka-Pilipczuk 2018) or preediting and post-editing of machine-translated texts (Varga 2016).

Intercultural communication became a topical issue in the 1980s and 1990s due to the developments of what we call the global village (Samovar-Porter 1997). At the same time, translation and interpretation theorists began to define translation and interpreting as mediation between cultures, as a form of intercultural communication (Bassnett 1991, Katan 2000). This implies that linguistic mediation can be seen not only as a process of understanding languages but also understanding cultural frames and involving cross-cultural transfer. As a more recent development in the digital age, the term interculturality is being replaced by transculturalism since intercultural thinking implies clear borders between one's own culture and foreign cultures. Thus, the term transcultural communication is more applicable to modern translation studies and the description of modern linguistic mediation (Schippel 2012, Hepp 2015).

The present time is often labelled as the "digital age". According to the Cambridge English Dictionary, it is the time "when most information is in the digital form" ${ }^{1}$ It is characterized by the fact that the use of digital technology is prevalent in all walks of life, and the spread of ICTs has radically changed the way we work, live, spend our free time, or communicate. Their impact is felt in very different areas of professional activity such as medicine, teaching and learning, farming, or business.

Globalization and the ubiquitous nature of ICTs, digital content, and information have resulted in the fact that our world has become interconnected. Furthermore, digital interaction is by now mostly cloud-based. In his seminal work Translation in the Digital Age, Cronin (2013) suggests that the digital age has resulted in a shift from an "information society" towards an "interaction society", and that the digital age is becoming an interaction age.

Linguistic mediation has been impacted to a great extent by the above-mentioned changes. The professions traditionally called "translation" and "interpreting" have been transformed by the digital revolution. In times of upheaval, profound changes can be felt in the market, the working environment, the conditions and processes as well as in the way language mediators work, the tasks they carry out, and the roles they play in the translation process. In what follows, we shall focus on these major changes and highlight the latest developments first in the field of translation and then in interpreting.

1 https://dictionary.cambridge.org/dictionary/english/digital-age 


\section{The language industry}

One of the consequences is the emergence of a global language industry. The LIND (Language Industry) Expert Group, whose task consists in providing the Directorate-General for Translation of the European Commission with expertise on the translation industry, defined the language industry as the professionals working in translation, interpreting, subtitling and dubbing, localization, language technology tools development, international conference organization, language teaching, and linguistic consultancy. ${ }^{2}$

Language "industry" implies a certain size. The Size of the Language Industry in the $E U$ published in 2009 estimated that the size of the whole language industry in the EU Member States was worth 8.4 billion EUR in 2008. This figure includes translation, interpreting, software localization and website globalization, language technology tool development, language teaching, language consultancy, organizing international conferences with multilingual requirements. The value of the translation and interpreting sector including software localization and website globalization was estimated to be worth 5.7 billion EUR in 2008 .

The same study proposed an annual compound growth rate of $10 \%$, resulting in an estimated value of the language industry of 16.65 billion EUR in 2015. A more recent study, the 2019 Language Industry Survey states that in the EU:

[c]ompanies (and to a lesser extent independent professionals) continue to see a growth of the global translation activity and expect this trend to even slightly increase. $69 \%$ of the responding companies expect a further increase in activity, against only $5 \%$ a decrease. This further improvement compared to 2017 and 2018 is clearly fuelled by the uninterrupted industry growth that companies have been reporting since 2014 .

As for the size of the global language industry, one of the best-known surveys is the Annual Review of the Services and Technology Industry That Supports Translation, Localization, and Interpreting published by CSA Research. The 2018 Language Services Market Review reports a 46.52 billion USD market and forecasts further growth, making the estimated value of the market worth 56.18 billion USD in 2021. Conin (2013) also states that the "demand for translation keeps growing apace in the contemporary world" (Conin 2013: 10). Thus, we can conclude that estimates concerning the current and future size of our industry are quite positive.

In addition to size, the term "industry" also implies a certain character and structure. Language industry and translation/interpreting have become globalized language services, where the proximity of the service provider to the client is no

2 https://ec.europa.eu/info/departments/translation/language-industry-platform-lind_en 
longer a requirement - one of the achievements of our age. Modern translators often work on online projects in teams fulfilling different roles/tasks (translators, terminologists, revisers, etc.). Their teamwork is based on cooperation requiring highly developed interpersonal skills. They share the so-called product of the tasks they have been assigned and thus contribute to the final success of the project.

The fact that translation projects are very often organized as teamwork puts intellectual property and copyright of technical translations, one of the oldest and most controversial legal issues concerning translators, into a new light. The principles of intellectual property protection were laid down by the Berne Convention for the Protection of Literary and Artistic Works, signed as early as in 1886. ${ }^{3}$ Although it considers translations as creative works (Esteves 2005) and as such ensures intellectual protection for translated works (see also Translation and Intellectual Property Rights. Final report - Study 2014), even translators of literary works find it difficult to enforce their rights (Esteves 2005). In the case of texts translated in projects based on teamwork, where the final product is the result of shared work and several revised versions, the copyright and intellectual property issue seems to lose its relevance.

Growing demand on the translation services market has resulted not only in the necessity of producing translations in teamwork but also in the fact that these translations increasingly have to be completed very fast. This has become possible by the technological advances we have seen with the advent of new technologies such as translation software and terminological databases (see below). Another requirement is the excellent quality of service, a top priority for clients, followed by the quality of deliverables in the third place (2019 Language Industry Survey). The term "deliverables" brings us to "commodification", a relatively new phenomenon on the translation services market. In this sense, with the exception of maybe literary and film translation, translation is not considered as an intellectual activity, but rather translations become industrial products to be sold on a market, where profit maximization and price pressures are frequent. In fact, the 2019 Language Industry Survey found that "all respondent types [companies, independent professionals, translation department and training institutes] see price pressure as the main negative trend".

\section{From CAT to HAT}

Translators in the digital age have less and less time to carry out high-quality work and produce translations of an ever-increasing amount of texts. They are able to fulfil these seemingly contradictory requirements because of the technological development and globalization: not only can they share work and distribute 
tasks in cloud-based online teams but also various IT tools have been created to this end. The term CAT, i.e. computer-assisted translation appeared in the 1990s with the spread of personal computers and the advent of the Internet, marking a watershed in the working environment of the translator, who had used pens, paper-based dictionaries as work tools and went to libraries or saw specialists if they needed terminological help. Back then, CAT tools basically meant their PC and the word processing software they were using. Since then, CAT has become a broader term and covers every tool that helps the work of translators (Zetzsche 2008 in Ábrányi 2016). These include terminology management tools, corpus analysis tools but also text editors and spell checkers, online or offline dictionaries, glossaries, reference materials, grammatical aids, parallel texts, OCR (optical character recognition) or DTP (desktop publishing) programs as well as tools for project management and administration (as argued in Bowker 2002, Craciunescu et al. 2004 in Ábrányi 2016).

A smaller segment of CAT tools is called translation environment tools (TEnT), which "integrate important features, such as translation memory, a terminology tool, an alignment tool, or an analysis tool" (Ábrányi 2016: 167). These tools not only ensure higher productivity but they "allow for a higher level of consistency with regard to terminology and style' (Ábrányi 1916: 175), thus improving quality.

One of the most recent changes in our profession consists in the shift from CAT, when computers helped humans, to HAT, human-assisted translation, where humans help computers with automated machine translation (MT). MT is not a new phenomenon; it has been around for over 50 years now. It has known three development stages: rule-based, statistical, and neural machine translation (NMT). The novelty resides in the fact that NMT seems to have brought about a breakthrough and produces much higher quality translations than before. The underlying technologies include big data and artificial intelligence (AI). This evolution is reflected by the sophistication of MT at the European Commission's Directorate General for Translation, where the three main periods are the following: (1) EC Systran/ECMT from ca. 1976 to 2010; (2) MT@EC from 2013 to 2018; (3) eTranslate from 2018 (Rummel 2019).

The spread of automated translation systems is fuelled by the growing demand on the translation market (Mileto 2011, Taravella-Villeneuve 2013, 2018 Language Services Market Review, 2019 Language Industry Survey), which cannot be satisfied by humans for lack of translation specialists (Taravella-Villeneuve, 2013). At the same time, translator training programmes are encouraged to incorporate/integrate MT into their curricula by the new competence framework elaborated by the EMT (European Masters in Translation). Their aim is "to consolidate and enhance the employability of graduates of master's degrees in translation throughout Europe", placing special emphasis on MT and automated translation-related skills and competences such as pre-editing and post-editing, 
as well as mastering the basics of MT and its impact on the translation process and assessing the relevance of MT systems in a translation workflow and implement the appropriate MT system where relevant (EMT Competence Framework 2017). It is a significant change compared to the 2009 version drafted by the EMT Expert Group, when translation students were required merely to "know the possibilities and limits of MT" (Gambier et al. 2009).

\section{New tasks and roles}

All this transformation enabled by technological development has led to the appearance of new tasks and roles to be fulfilled by linguistic mediators, nowadays called LSPs (Language Service Providers). This term has in fact given rise to some confusion because it is interchangeably used to refer to individual professionals and companies. However, it underlines the fact that translators and interpreters "are no longer just expected to mediate between languages in written or spoken form. [They] must offer a complex set of services" (Horváth 2016: 13).

LSPs are very often required to carry out various tasks in addition to translation and act as terminologists, revisers, language consultants, localizers, pre-editors, or post-editors. Furthermore, new professions have appeared on the market such as translation project manager, vendor manager, language engineer, or translation DTP (Desktop Publishing) specialist (Horváth 2016c).

\section{New technologies in interpreting}

So far, we have predominantly focused on translation-related developments. In what follows, we shall discuss the changes specific to interpreting, which have occurred with the advent of new information and communication technologies gaining ground on the interpretation market. First, interpreters use a wide range of technological devices when preparing for an assignment. In addition, the expression "digital booth" is used more and more often. It refers to the fact that portable electronic devices (laptops, tablets, iPads, etc.) have become indispensable working tools, facilitating the interpreter's performance. Such devices are used not only prior to the conference but also during the interpreting process in order to follow the slideshows of the speeches received in advance or acquired on the spot or even to look up terms and expressions they hear that are not readily available to them in the activated part of their mental lexicon in real time (Horváth 2016b: 184).

Such technological advances as remote and computer-assisted interpreting (CAI) as well as automated machine interpreting have been gaining ground on the 
international interpreting market. Remote interpreting (RI) refers to the situation when the interpreter is not in the same room as the speaker and the participants of the interpreted event (Braun 2015, Moser-Mercer 2005, Mourourakis 2010). There are different types of remote interpreting, including telephone- or videoconference-mediated events. This technology together with those available in the digital booth are defined by Fantinuoli as "setting-oriented technologies", i.e. "ICT tools and software surrounding the interpreting process" (Fantinuoli 2017a: 156).

CAI is a more recent development, which is gaining momentum on the interpretation market. In Fantinuoli's classification, CAI tools are processoriented technologies comprising "terminology management systems, knowledge extraction software, corpus analysis tools and the like". What makes them processoriented is the fact that "they are designed to support the interpreter during the different sub-processes of interpreting, and consequently, in the various phases of assignment [...] independently of the modality" (Fantinuoli 2017a: 156). In addition, various tools, such as interpreter-specific glossary management systems, ${ }^{4}$ have been developed lately (Costa et al. 2014, Fantinuoli 2017b). These aim at facilitating terminology work during interpreting by showing keywords in the source and target languages as well as names and figures. They are still not used very widely by interpreters (Riccardi et al. 2019), and whether or not they mean too big additional cognitive burden for the conference interpreter remains to be researched (as argued in Gile 2009).

Following the trend of Neural Machine Translation, the latest development is that high tech companies have been trying to create the AI (artificial intelligence) interpreter using Big Data - so far, with little success. ${ }^{5}$ Although fully automated machine interpreting has not been achieved yet, there are various consecutive and simultaneous machine interpreting devices which aim at bridging the language gap between speakers of different languages. These tools "have been developed for a limited number of specific communication situations. They are used to interpret the most frequent pre-recorded phrases, questions between different languages in well-defined contexts such as travel, humanitarian missions, medical care, wars" (Horváth 2016b: 187).

4 Riccardi et al. (2019) have collected the following examples of such software: InterpretBank (http://www.interpretbank.com/); Intragloss (http://intragloss.com/); Interplex (http://www. fourwillows.com/interplex.html); LookUp (http://www.lookup-web.de/); Terminus (http://www. wintringham.ch/cgi/ayawp.pl/t/terminus); Interpreter's help (https://interpretershelp.com/).

$5 \quad$ AI Interpreter Fail at China Summit Sparks Debate about Future of Profession. https://slator.com/features/ai-interpreter-fail-at-china-summit-sparks-debate-about-future-ofprofession/. 


\section{Summary}

Technological advances and new ICTs have impacted on translation and interpreting, and they are gaining ground in the language industry in general as well as on the translation market. New technology-driven inventions and tools appear regularly in our working environment. The ultimate aim of most developers seems to be to reach a level where fully automated translation and interpreting becomes possible.

Technological development has been experienced on the translation market earlier and to a greater extent than on the interpretation market. One reason for this might lie in the fact that the translation market is bigger and wider, which means that there is more demand for human-made and automatically generated translations as well. Another reason is that the automation of interpretation must take into account a number of real-time variables too, which do not appear during translation. An interpreted speech is delivered in real time, and interpreters are required to work in an "online" mode and produce the targetlanguage speech instantly. This means that it is not possible to re-edit before or post-edit after an utterance.

As for the use of CAI tools, such as terminology management software during the interpretation process, interpreters seem to be reluctant to embrace them. One reason might be that their interpreting training had focused on the communicational and cognitive aspects of professional interpreting and prepared interpreters to use their own resources during assignments. Nevertheless, some modern interpreter training curricula do include some training on new technologies (Riccardi et al. 2019, EMCI Core Curriculum). Another reason is the fact that the cognitive burden on interpreters during interpreting, independently from the modalities, is heavy enough. Using a terminology management software in the digital booth would mean an additional "effort" (as argued in Gile 2009), which interpreters are not used to and trained for.

In conclusion, although technological developments have transformed our whole world and several industries, there are still jobs where humans will be needed in the future. These will be jobs which require some specific and unique skills. Among the ten vital skills of future workers enumerated by Marr (2019) are creativity, emotional intelligence, analytical (critical) thinking, judgement and decision making, interpersonal communication skills, diversity, and cultural intelligence. The good news for our profession is that there are certain types of translation, such as literary or film translation, as well as certain types of interpreting, such as community, court, and conference interpreting, which require a great amount of these skills from language professionals and which cannot be found in machines yet. 


\section{References}

Bassnett, S. 1991. Translation Studies. London: Routledge.

Braun, S. 2015. Remote interpreting. In: H. Mikkelson-R. Jourdenais (eds), Routledge Handbook of Interpreting. London: Routledge. 352-367.

Corina, D. P.-Vaid, J. 1994. Lateralisation for shadowing words versus signs: A study of ASL-English interpreters. In: S. Lambert-B. Moser-Mercer (eds), Bridging the gap. Amsterdam-Philadelphia: John Benjamins Publishing Company. 237-248.

Costa, H.-Corpas Pastor, G.-Durán Muñoz, I. 2014. Technology-assisted interpreting. Multilingual 25(3), 27-32.

Cronin, M. 2013. Translation in the digital age. London-New York: Routledge.

Fantinuoli, C. 2017a. Computer-assisted interpretation: Challenges and future perspectives. In: I. Durán-G. Corpas, (eds), Trends in e-tools and resources for translators and interpreters. Leiden: Brill.

Felekné Csizmazia, E. 2014. A fordítás és a tolmácsolás határán. A blattolás kutatása. Fordítástudomány 16(2): 24-36.

Gile, D. 2009. Basic concepts and models for interpreter and translator training. Revised edition. Amsterdam: John Benjamins.

Hepp, A. 2015. Transcultural communication. Chichester: Wiley Blackwell.

Horváth, I. 2013. Bírósági tolmácsolás. Budapest: ELTE Eötvös Kiadó.

Katan, D. 2000 Translating cultures. An introduction for translators, interpreters and mediators. Manchester: St. Jerome Publishing.

Moser-Mercer, B. 2005. Remote interpreting: Issues of multi-sensory integration in a multilingual task. Meta 50(2): 727-738.

Mouzourakis, P. 2010. Remote interpreting - A technical perspective on recent experiments. Interpreting 8(1): 45-66.

Parkin, Ch. 2010. La traduction à vue - une forme hybride entre l'interprétation et la traduction écrite. In: M. Iliescu-H. Siller-Runggaldier-P. Danler, (eds), XXVe CILPR Congrès International de Linguistique et de Philologie Romanes Innsbruck, 3- 8 septembre 2007. Berlin-New York: de Gruyter. 613-622.

Riccardi, A.-Čeňková, I.-Tryuk, M.-Maček, A.-Pelea, A. (Projects Committee, EMCI Consortium). 2019. Survey of the use of new technologies in conference interpreting courses. In: Rodríguez Melchor, D. M.-Horváth, I.-Ferguson, K. (eds), The role of technology in conference interpreter training. Oxford: Peter Lang (in press).

Samovar, L. A.-Porter, R. E. 1997. Intercultural communication. Belmont: Wadsworth Publishing Company.

Schippel, L. 2012. Between consensus and the dissolution of boundaries: On the transculturality of communicative action. Berlin: Frank \& Timme. 


\section{Web Sources}

Ábrányi, H. 2016. Translation environment tools. In: I. Horváth (ed.), The modern translator and interpreter. Budapest: Eötvös University Press. 167-182. http://www.eltereader.hu/media/2016/04/HorvathTheModernTranslator.pdf (downloaded on: 1 July 2019).

EMCI Core Curriculum. 2017. https://www.emcinterpreting.org/course-structure (downloaded on: 1 of July 2019).

EMT Competence Framework - 2017. https://ec.europa.eu/info/sites/info/files/ emt_competence_fwk_2017_en_web.pdf (downloaded on: 1 July 2019).

Esteves, L. M. R. 2005. Intellectual property and copyright: The case of translators. Translation Journal 9(3). https://translationjournal.net/journal/33copyright. htm (downloaded on: 1 July 2019).

Fantinuoli, C. 2017b. Computer-assisted preparation in conference interpreting. Translation \& Interpreting 2(9). http://www.trans-int.org/index.php/transint/ article/view/565 (downloaded on: 1 July 2019).

Gambier, Y. (EMT Expert Group). 2009. Competences for professional translators, experts in multilingual and multimedia communication. https://ec.europa.eu/ info/sites/info/files/emt_competences_translators_en.pdf (downloaded on: 1 July 2019).

Horváth, I. 2016a. Foreword. In: I. Horváth (ed.), The modern translator and interpreter. Budapest: Eötvös University Press. 13-14. http://www.eltereader. hu/media/2016/04/HorvathTheModernTranslator.pdf (downloaded on: 1 July 2019).

2016b. Information and communication technologies in interpreting machine interpretation. In: I. Horváth (ed.), The modern translator and interpreter. Budapest: Eötvös University Press. 183-192. http://www.eltereader.hu/ media/2016/04/HorvathTheModernTranslator.pdf (downloaded on: 1 July 2019).

(ed.). 2016c. The modern translator and interpreter. Budapest: Eötvös University Press. http://www.eltereader.hu/media/2016/04/ HorvathTheModernTranslator.pdf (downloaded on: 1 July 2019).

Marr, B. 2019. The 10 vital skills you will need for the future of work. https:// www.forbes.com/sites/bernardmarr/2019/04/29/the-10-vital-skills-you-willneed-for-the-future-of-work/\#2825d6893f5b (downloaded on: 1 July 2019).

Mileto, F. 2011. From computer-assisted translation to human-assisted translation. Tralogy - Les 3 et 4 mars 2011 - Session 3 - Machine and human translation: Finding the fit? / TA et Biotraduction. http://lodel.irevues.inist.fr/tralogy/ index.php?id=217\&format=print (downloaded on: 1 July 2019). 
Rinsche, A.-Portera-Zanotti, N. 2009. The size of the language industry in the EU. https://publications.europa.eu/en/publication-detail/-/publication/9a68479a1c07-4c43-8d1a-8d49782c0808 (downloaded on: 1 July 2019).

Rummel, D. 2019. Beyond MT? A few premature reflections on the use of MT in translation. TAUS Global Content Summit Amsterdam, 6 March 2019. https:// www.slideshare.net/TAUS/taus-global-content-summit-amsterdam-2019beyond-mt-a-few-premature-reflections-on-the-use-of-ai-in-translation-bydieter-rummel-head-of-informatics-dgt-european-commission (downloaded on: 1 July 2019).

Taravella, A.-Villeneuve, A. O. 2013. Acknowledging the needs of computerassisted translation tools users: The human perspective in human-machine translation. JoSTrans 19. http://www.jostrans.org/issue19/art_taravella.pdf (downloaded on: 1 July 2019).

The language services market: 2018. Annual review of the services and technology industry that supports translation, localization, and interpreting. https:// insights.csa-research.com/reportaction/48585/Marketing (downloaded on: 1 July 2019).

Translation and intellectual property rights. Final report - Study. 2014. https:// publications.europa.eu/en/publication-detail/-/publication/e079e290-e250482d-9d4f-dae566ba67ff/language-en (downloaded on: 1 July 2019).

Varga, Á. 2016. Machine translation. In: I. Horváth (ed.), The modern translator and interpreter. Budapest: Eötvös University Press. 153-165. http://www. eltereader.hu/media/2016/04/HorvathTheModernTranslator.pdf (downloaded on: 1 July 2019).

2019 Language Industry Survey - Expectations and concerns of the European language industry. https://ec.europa.eu/info/sites/info/files/2019_language_ industry_survey_report.pdf (downloaded on: 1 July 2019). 